\title{
Direct spectroscopic speciation of the complexation of U(VI) in acetate solution
}

\author{
Günther Meinrath • Dorota Kwiatek • \\ Zbigniew Hnatejko $\cdot$ Stefan Lis
}

Received: 10 February 2014 / Accepted: 3 July 2014/Published online: 24 July 2014

(C) The Author(s) 2014. This article is published with open access at Springerlink.com

\begin{abstract}
As a result of systematic UV-Vis absorption spectroscopy studies in the $\mathrm{U}(\mathrm{VI})$ acetate system, the single component spectrum of $\left[\mathrm{UO}_{2} \mathrm{CH}_{3} \mathrm{COO}\right]^{+}$with characteristic parameters was evaluated and applied in quantitative deconvolution of multicomponent spectra. Free acetate concentrations were obtained by the use of geochemical and probabilistic modelling codes. A total of $51 \mathrm{UV}-\mathrm{Vis}$ spectra were collected in a wide range of experimental conditions where coordination of U(VI) by acetate ion was indicated by characteristic variations in the spectra structure as compared to $\mathrm{UO}_{2}{ }^{2+}$. Using chemometric data analysis, the resulting factor structure was evaluated to obtain a subset of 14 spectra holding only one coordinated species next to $\mathrm{UO}_{2}{ }^{2+}{ }_{(\mathrm{aq})}$. The molar absorption coefficient for the U(VI) monoaceto species was estimated as $\varepsilon_{418}=17.8 \pm 1 \mathrm{dm}^{3} \mathrm{~mol}^{-1} \mathrm{~cm}^{-1}$. Spectral deconvolution was used to obtain an estimate of the species concentrations which allowed to calculate for each sample the free acetate concentration, the total U(VI) amount and, eventually, to estimate the formation quotient $\mathrm{lg}$ $\beta_{11}=2.8 \pm 0.3$ of $\mathrm{UO}_{2}\left(\mathrm{CH}_{3} \mathrm{COO}\right)^{+}$.
\end{abstract}

Keywords UV-Vis spectroscopy - Absorption spectra . Coordination chemistry $\cdot$ Stability constant

G. Meinrath

RER Consultants, Fuchsbauerweg 50, 94036 Passau, Germany

D. Kwiatek $\cdot$ Z. Hnatejko $\cdot$ S. Lis $(\square)$

Department of Rare Earth, Faculty of Chemistry, Adam

Mickiewicz University, Grunwaldzka 6, 60-780 Poznan, Poland

e-mail: blis@amu.edu.pl

\section{Introduction}

Acetate, $\mathrm{CH}_{3} \mathrm{COO}^{-}$, is the salt of the monoprotic acetic acid, $\mathrm{CH}_{3} \mathrm{COOH}$. The protonation constant $K_{\mathrm{A}}$ of acetic acid is reported to be $\mathrm{p} K_{\mathrm{A}}=4.76[1,2]$ in diluted aqueous solutions at $298 \mathrm{~K}$. Under those conditions, hexavalent uranium occurs exclusively as linear dioxo entity, $\mathrm{UO}_{2}{ }^{2+}$ [3]. This dioxo cation is almost always coordinated in the plane equatorial to the axial uranyl oxygens by four, five, or six neighbours. Coordination of the uranyl(VI) ion by acetato ligands may occur in a rather limited range between pH 1.9 and pH 5.0. At values below pH 1.9, the free acetate concentration is too low for significant $\mathrm{U}(\mathrm{VI})$ coordination, even in acetate brines. At values above $\mathrm{pH}$, the solubility of $\mathrm{U}(\mathrm{VI})$ with respect to $\mathrm{UO}_{3} \cdot 2 \mathrm{H}_{2} \mathrm{O}$ is limiting the $\mathrm{U}(\mathrm{VI})$ concentration except at total acetate concentrations $>10^{-2}$ mol dm${ }^{-3}$. Here, however, complexation by atmospheric $\mathrm{CO}_{2}$ may interfere because of the very high coordination tendency of $\mathrm{U}(\mathrm{VI})$ and $\mathrm{CO}_{3}{ }^{2-}$ [4]. Experimental speciation of $\mathrm{U}(\mathrm{VI})$ should consider the onset of hydrolysis at about pH 3 [5], which may interfere. To circumvent, both precipitation and hydrolysis of U(VI) high concentrations of acetate are required in solution.

Considering the narrow field of stability of U(VI) acetate species, a surprising amount of work has been devoted to the study of the $\mathrm{U}(\mathrm{VI})$ acetate interaction, both on the experimental [6-12] and the theoretical level [13-17]. The literature given is but a selection from the past decade and the abundance available. Three groups can be distinguished: crystallographic studies [6-8], analytical studies often involving very advanced equipment like synchrotron sources [9-12], and quantum chemical numerical calculations [13-17]. Considering the wide range of experimental techniques applied to the study of U(VI) acetate interaction in aqueous solutions, e.g. infrared and Raman spectroscopy 
$[18,19]$, potentiometry and calorimetry [20], capillary electrophoresis [12], X-ray absorption [16, 21], mass spectrometry [13, 15], ion exchange chromatography [22], a standard method of U(VI) speciation in aqueous solution is almost missing: UV-Vis absorption spectroscopy. Some early work is available [23-25], however, without detailed information on single component characteristics like band position and molar absorptions. Görrler-Walrand and de Jagere [26] report a single component spectrum of $\mathrm{UO}_{2} \mathrm{CH}_{3} \mathrm{COO}^{+}$without further information on the determination and characteristics of this spectrum. Recently, single component UV-Vis absorption spectra of U(VI) acetato species have been proposed from a factor analysis study, again without further information even on very basic characteristics of the spectra, e.g. molar absorptions. The wavelength range was limited to a rather narrow region of $400-470 \mathrm{~nm}$, thus omitting the characteristic absorptions of U(VI) in the range 340-400 $\mathrm{nm}$ [27]. The onset of the strong absorption towards the UV is a characteristic feature for each $\mathrm{U}(\mathrm{VI})$ species and a crucial proof for the reliability of proposed single component spectra in peak deconvolution studies. Successful applications of single component $\mathrm{U}(\mathrm{VI})$ spectra in the $\mathrm{U}(\mathrm{VI})$-acetate system are not to our knowledge.

Therefore, we have studied the U(VI) acetate system systematically by UV-Vis absorption spectroscopy. For the first time, we report the single component spectrum of $\mathrm{UO}_{2} \mathrm{CH}_{3} \mathrm{COO}^{+}$together with its characteristic parameters and show its applicability to the quantitative deconvolution of mixed spectra from the U(VI) acetate system. This data is of basic importance to compare U(VI) acetate complexation with other $\mathrm{U}(\mathrm{VI})$ carboxylate interactions up to naturally occurring organic materials where carboxylate groups are considered as functional groups relevant for $\mathrm{U}(\mathrm{VI})$ binding [14].

\section{Results and discussion}

A set of $14 \mathrm{U}(\mathrm{VI})$ absorption spectra are given in Fig. 1, normalised to the total $\mathrm{U}(\mathrm{VI})$ concentration. This presentation reveals a systematic increase in the molar absorption from $9.7 \mathrm{dm}^{3} \mathrm{~mol}^{-1} \mathrm{~cm}^{-1}$ at $413.8 \mathrm{~nm}$ to about $16.5 \mathrm{dm}^{3} \mathrm{~mol}^{-1} \mathrm{~cm}^{-1}$ at $416.9 \mathrm{~nm}$. A molar absorption of $9.7 \mathrm{dm}^{3} \mathrm{~mol}^{-1} \mathrm{~cm}^{-1}$ at $413.8 \mathrm{~nm}$ is known for the free $\mathrm{UO}_{2}{ }^{2+}$ ion in aqueous solutions. The increase in molar absorption in the characteristic band of $\mathrm{U}(\mathrm{VI})$ correlates with the ratio of free acetate and total U(VI) concentration, that is, with increasing coordination of $\mathrm{UO}_{2}{ }^{2+}$ by acetate. The concentration ratio given in Fig. 1 does not vary systematically with the change in the absorption (e.g. at the wavelength of $413.8 \mathrm{~nm}$ ). Such a systematic change should not be expected. First, the ratio holds the total

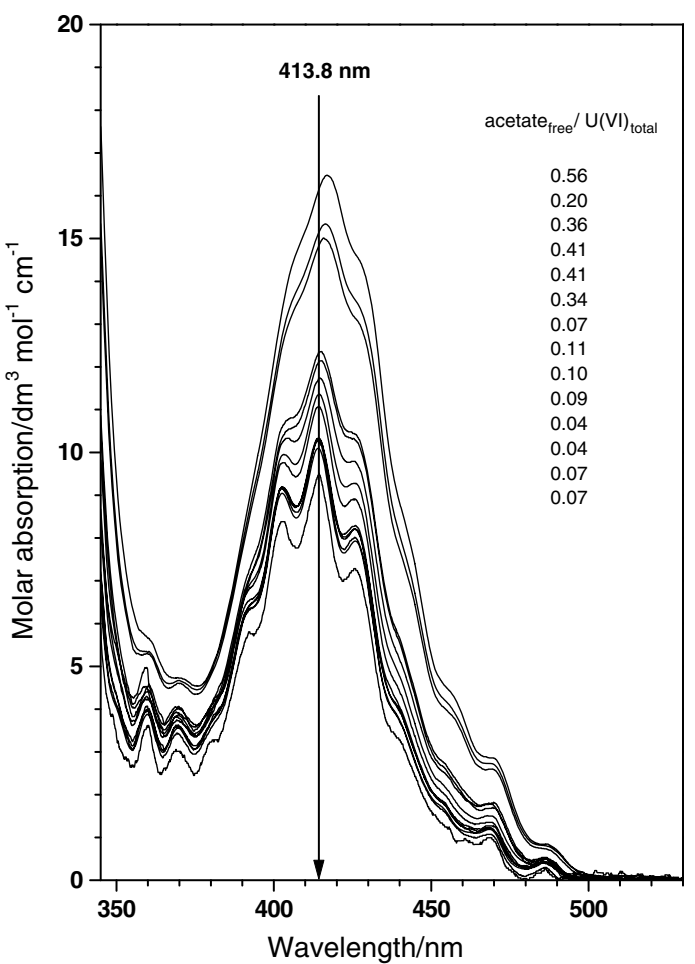

Fig. 1 Absorption curves of 14 experimental spectra of U(VI) collected in $\mathrm{U}(\mathrm{VI})$ acetate medium at varying $\mathrm{pH}$ and total $\mathrm{U}(\mathrm{VI})$ and acetate concentrations. Data is normalised by the U(VI) concentration. Sequence of spectra corresponds to the sequence of concentration ratios

$\mathrm{U}(\mathrm{VI})$ concentration, not the free U(VI) concentration. Second, both the calculated free acetate concentration and the total $\mathrm{U}(\mathrm{VI})$ concentration are experimental quantities which are associated with a measurement uncertainty. Forming the ratio of uncertain data further enhances the uncertainty. Nevertheless, the observed absorption and the concentration ratio are strongly correlated (Pearson correlation $r=0.8$ ).

No isosbestic point is observed. Coordination of U(VI) by acetate causes a weak band shift to longer wavelengths, barely visible at the most intense spectra in Fig. 1. A hyperchromic effect is intensifying the absorption. Increasing coordination by acetate also causes a bathochromic shift of the steep absorption band in the region below $350 \mathrm{~nm}$.

The UV-Vis spectroscopic study of the U(VI) acetate system is limited by four constraints. The first constraint is the low molar absorption of $\mathrm{UO}_{2}{ }^{2+}(\mathrm{aq})$ in the characteristic absorption bands about $413.8 \mathrm{~nm}$. The second constraint is the onset of $\mathrm{U}(\mathrm{VI})$ hydrolysis at values between $\mathrm{pH} 3.3$ and pH 3.7 (depending on the total U(VI) concentration). Third, the acetate ligand is formed from acetic acid with a $\mathrm{p} K_{\mathrm{A}}=4.76[1,2]$.

Fourth, the solubility of $\mathrm{U}(\mathrm{VI})$ in solution is limited by the solid $\mathrm{UO}_{3} \cdot 2 \mathrm{H}_{2} \mathrm{O}$. Figure 2 illustrates these constraints, 
Table 1 Thermodynamic parameters used for stability field simulation in Fig. 2

\begin{tabular}{lcl}
\hline Species & Formation constant/acidity constant & References \\
\hline $\mathrm{CH}_{3} \mathrm{COO}^{-}$ & -4.76 & {$[45]$} \\
$\left(\mathrm{UO}_{2}\right)_{2}(\mathrm{OH})_{2}^{2+}$ & -6.14 & {$[28]$} \\
$\left(\mathrm{UO}_{2}\right)_{3}(\mathrm{OH})_{5}^{+}$ & -17.30 & {$[29,30]$} \\
$\mathrm{UO}_{2} \mathrm{CH}_{3} \mathrm{COO}$ & 2.80 & {$[45]$} \\
$\mathrm{UO}_{2}\left(\mathrm{CH}_{3} \mathrm{COO}\right)_{2}$ & 4.70 & {$[45]$} \\
$\mathrm{UO}_{2}\left(\mathrm{CH}_{3} \mathrm{COO}\right)_{3}^{-}$ & 5.10 & {$[45]$} \\
$\mathrm{UO}_{2} \mathrm{CO}_{3}{ }^{\circ}$ & 9.10 & {$[32]$} \\
\hline
\end{tabular}

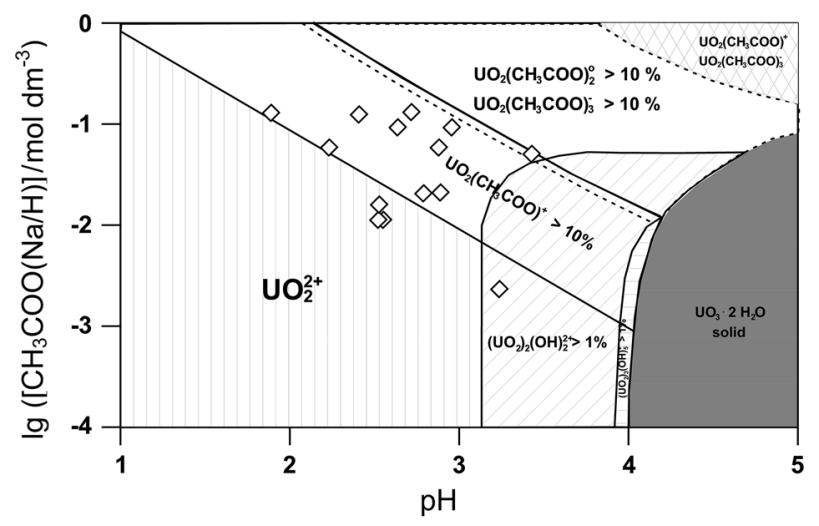

Fig. 2 Constraints in the system U(VI) acetate in the range $\mathrm{pH} 1$ to $\mathrm{pH} 5$ and total acetate concentrations varying from $10^{-4}$ to $1 \mathrm{~mol} \mathrm{dm}^{-3}$. The diagram is calculated for a fixed total U(VI) concentration of $0.01 \mathrm{~mol} \mathrm{dm}^{-3}$ from data collected in Table 1 . Diamond-shaped symbols indicate locations of experimental samples. The varying U(VI) concentrations of these samples does not play a role except in case of oligomeric hydrolysis product formation

where stability regions of various species are given on basis of geochemical modelling using data from Table 1. The diamond-shaped symbols indicate the 14 samples where coordination of the free uranyl ion, presumably by acetate, was observed.

Figure 2, which is deduced from literature data, suggests that the monoacetato species of U(VI) forms only at quite acidic $\mathrm{pH}$ and rather high total acetate concentrations without interference from other species. The stability fields for the acetato species have been selected to represent conditions where the species concentrations are calculated to be above $10 \%$ of the total species concentrations. For the hydrolysis species, the stability fields enclose conditions where species concentrations are above $1 \%$.

The distinction is due to the difference in molar absorptions. While the oligomeric hydrolysis products $\left(\mathrm{UO}_{2}\right)_{2}(\mathrm{OH})_{2}^{2+}$ and $\left(\mathrm{UO}_{2}\right)_{3}(\mathrm{OH})_{5}^{+}$have molar absorptions of about $100 \mathrm{dm}^{3} \mathrm{~mol}^{-1} \mathrm{~cm}^{-1}(421.8 \mathrm{~nm})$ [28] and about $475 \mathrm{dm}^{3} \mathrm{~mol}^{-1} \mathrm{~cm}^{-1}(429.0 \mathrm{~nm})$ [29], respectively, the acetato species have much lower molar absorptions in the range of the characteristic absorption band of $\mathrm{U}(\mathrm{VI})$. Hence, even minor amounts of oligomeric U(VI) hydrolysis products in a sample will affect an experimental UVVis spectrum. The respective stability field of a U(VI) diacetato species is represented in Fig. 2 by the region enclosed in dashed lines. In this region of the $\lg$ [acetate]$\mathrm{pH}$ diagram, all acetato species considered, $\mathrm{UO}_{2} \mathrm{CH}_{3}$ $\mathrm{COO}^{+}, \quad \mathrm{UO}_{2}\left(\mathrm{CH}_{3} \mathrm{COO}\right)_{2}{ }^{\circ}$, and $\mathrm{UO}_{2}\left(\mathrm{CH}_{3} \mathrm{COO}\right)_{3}^{-}$, are calculated to occur in solution with relative amounts above $10 \%$. Hence, direct spectroscopic speciation in such complex media requires accurate knowledge of the respective single component spectra of $\mathrm{U}(\mathrm{VI})$ acetato species to have a chance to be meaningful. In the crosshatched region in the upper right corner of Fig. 2, the monoacetato and the triacetato species of $\mathrm{U}(\mathrm{VI})$ are pre-

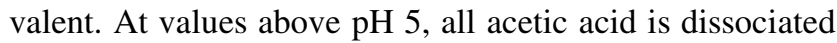
and further shift of $\mathrm{pH}$ does not significantly increase the amount of acetate ligand at a given total acetate concentration. Furthermore, under atmospheric conditions, carbonate will form in solution from $\mathrm{CO}_{2}$ dissolved in the solutions to become a potent competitor for U(VI) [30-32]. Thus, Fig. 2 summarises the essential features of the interaction of acetate with $\mathrm{U}(\mathrm{VI})$, against which the experimental findings from this study will be probed.

While concisely illustrating the U(VI)-acetate system, Fig. 2 is not considered as a guide for this investigation. Data evaluation is based, as far as possible, on model-free numerical and statistical models. No decision in this study is made with respect to Fig. 2.

From a total of 51 spectra collected at random in a wider range of conditions, 51 indicated coordinated $\mathrm{U}(\mathrm{VI})$ due to significant difference of the observed UV-Vis absorption spectrum from the well-known spectrum of $\mathrm{UO}_{2}{ }^{2+}$. From these 51 spectra, a set of spectra had to be found holding only $\mathrm{UO}_{2}{ }^{2+}$ and one further component. A larger number of spectra could readily be eliminated for their physicochemical state suggesting either influence of hydrolysis or formation of higher U(VI) acetato species. The remaining spectra were selected by either submatrix analysis [33] or computer-assisted target factor analysis (CAT) [34]. Thus, a data set with 14 spectra was obtained with the resulting factor structure given as a SCREE test [35] in Fig. 3. The first factor alone explains more than $90 \%$ of the observed variance. The second factor explains just $7 \%$ of the variance-that is the additional signal caused by the hyperchromic shift due to coordination by acetate.

The remaining factors explain random noise in the spectra contributing in sum less than $2 \%$ of the spectroscopic signal. It has been noted previously that a larger number of statistical criteria have been forwarded to identify the number of significant factors from a principal component analysis [36]. Due to the unavoidable presence of random noise in experimental data, none of these criteria 


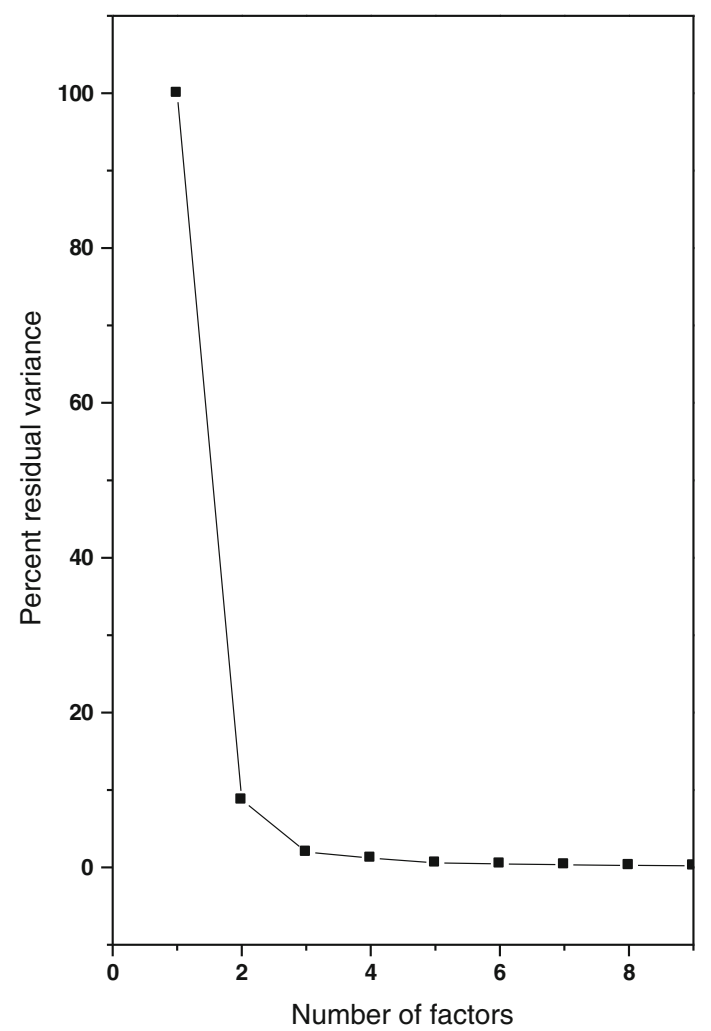

Fig. 3 Graphical representation of the SCREE test. The first factor explains about $85 \%$ of the experimental variance, the second about $7 \%$. The subsequent factors are not able to remove significant parts of the remaining variance

can be unambiguous. The researcher's choice must be judged on basis of the outcome of the overall analysis. In case of UV-Vis spectroscopic investigations, factor analysis forwards information which may serve as criteria. An example is the total $\mathrm{U}(\mathrm{VI})$ concentration in a sample. This concentration is known to the experimenter (within experimental uncertainty). Spectral deconvolution and factor analysis provide an estimate for this concentration by the sum of all U(VI) species quantitatively estimated in solution for all solutions based on the experimental spectra and the single component spectra included into the data analysis. Thermodynamic parameters, e.g. formation quotients of the species formed in solution, may serve as additional criterion.

The single component spectrum of $\mathrm{UO}_{2} \mathrm{CH}_{3} \mathrm{COO}^{+}$ resulting from these analyses is shown in Fig. 4, together with the spectrum of $\mathrm{UO}_{2}{ }^{2+}(\mathrm{aq})$ for comparison. The monoacetato species shows an absorption maximum at $418.0 \mathrm{~nm}$ with a molar absorption coefficient $\varepsilon_{418}=17.8 \pm 1 \mathrm{dm}^{3} \mathrm{~mol}^{-1} \mathrm{~cm}^{-1}$. The spectrum is given in Fig. 4 together with $0.68 \%$ (dashed) and $0.95 \%$ (dotted), obtained from a moving block bootstrap analysis [36]. Within the limits of precision, the UV-Vis absorption spectrum of $\mathrm{UO}_{2} \mathrm{CH}_{3} \mathrm{COO}^{+}$does not show a shift in the

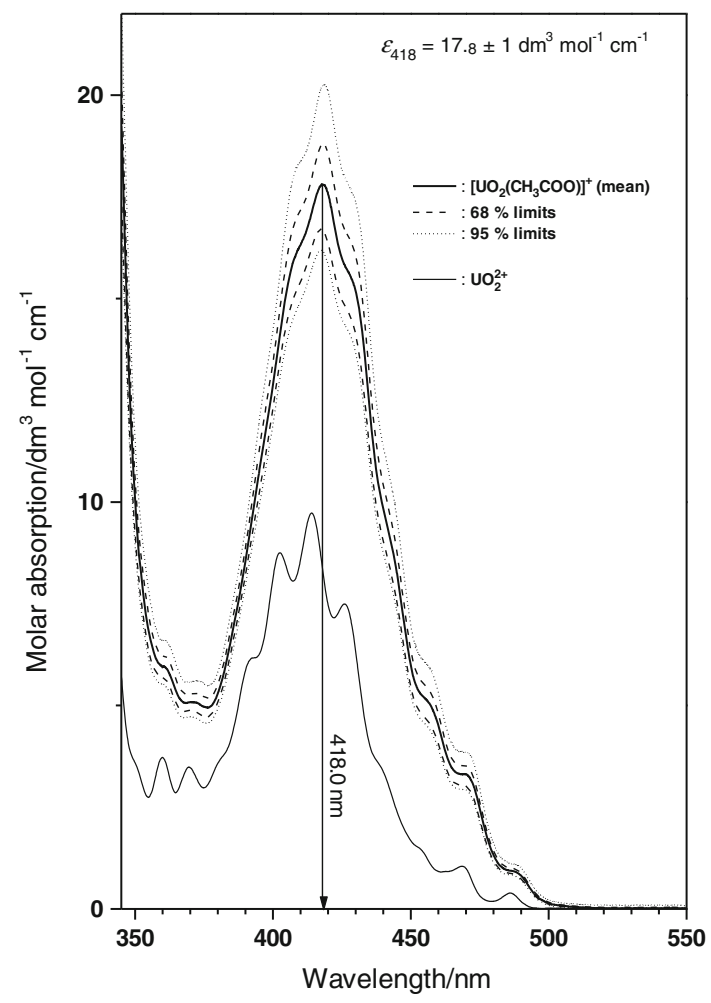

Fig. 4 Single component spectrum of $\mathrm{UO}_{2} \mathrm{CH}_{3} \mathrm{COO}^{+}$, compared to the spectrum of $\mathrm{UO}_{2}{ }^{2+}(\mathrm{aq})$. Absorption maximum of the characteristic band of $\mathrm{U}(\mathrm{VI})$ is found at $418.0 \mathrm{~nm}$. Molar absorption $\varepsilon_{418}=17.8 \pm 1.0 \mathrm{dm}^{3} \mathrm{~mol}^{-1} \mathrm{~cm}^{-1}$. Dashed lines give upper and lower 0.68 , dotted lines $0.95 \%$ uncertainty obtained from moving block bootstrap analysis

absorption maximum or the bands/shoulders in the characteristic absorption region of $\mathrm{U}(\mathrm{VI})$ compared to the absorption spectrum of $\mathrm{UO}_{2}{ }^{2+}$ except in the absorption maximum. The small difference in the position of the absorption maximum of the characteristic band of $\mathrm{U}(\mathrm{VI})$ causes the shift observed with the experimental spectra in Fig. 2.

The single component spectrum of $\mathrm{UO}_{2}\left(\mathrm{CH}_{3} \mathrm{COO}\right)^{+}$ (Fig. 4) is applied to the experimental spectra given in Fig. 1. The physical and chemical parameters of these samples are summarised in Table 2 together with results of a spectral deconvolution using the mean value spectra of $\mathrm{UO}_{2}{ }^{2+}$ and $\mathrm{UO}_{2} \mathrm{CH}_{3} \mathrm{COO}^{+}$from Fig. 4. Examples of this deconvolution are given in Figs. 5, 6 and 7 for three spectra with widely varying ratio of the U(VI) species concentrations. These spectra illustrate the power of the single component spectrum given in Fig. 4 to quantitatively interpret $\mathrm{U}(\mathrm{VI})$ solutions with widely varying physicochemical conditions.

These spectra demonstrate further that the bathochromic shift of the absorption edge to the UV region can be well interpreted quantitatively. These three spectra are the first examples to our knowledge where a single component 
Table 2 Results of spectral deconvolutions of $14 \mathrm{UV}-\mathrm{Vis}$ using single component spectra of $\mathrm{UO}_{2}{ }^{2+}$ and $\mathrm{UO}_{2} \mathrm{CH}_{3} \mathrm{COO}^{+}$

\begin{tabular}{llllllll}
\hline $\mathrm{pH}$ & $1 \mathrm{~g}\left[\mathrm{CH}_{3} \mathrm{COO}^{-}\right]_{\text {free }}$ & {$[\mathrm{U}(\mathrm{VI})] / \mathrm{mol} \mathrm{dm}^{-3}$} & {$[\mathrm{U}(\mathrm{VI})]_{\mathrm{cal}} / \mathrm{mol} \mathrm{dm}^{-3}$} & $\Delta / \%$ & {$\left[\mathrm{UO}_{2}^{2+}\right] / \mathrm{mol} \mathrm{dm}^{-3}$} & {$\left[\mathrm{UO}_{2} \mathrm{CH}_{3} \mathrm{COO}^{+}\right] / \mathrm{mol} \mathrm{dm}^{-3}$} & $\mathrm{lg} \mathrm{R}^{R}$ \\
\hline 1.9 & -3.629 & $2.42 \times 10^{-3}$ & $2.40 \times 10^{-3}$ & -0.8 & $2.16 \times 10^{-3}$ & $2.39 \times 10^{-4}$ & -0.96 \\
2.24 & -3.656 & $2.48 \times 10^{-3}$ & $2.45 \times 10^{-3}$ & -1.2 & $2.19 \times 10^{-3}$ & $2.58 \times 10^{-4}$ & -0.93 \\
2.42 & -3.090 & $2.42 \times 10^{-3}$ & $2.42 \times 10^{-3}$ & 0 & $1.73 \times 10^{-3}$ & $6.90 \times 10^{-4}$ & -1.20 \\
2.52 & -3.979 & $2.43 \times 10^{-3}$ & $2.44 \times 10^{-3}$ & 0.4 & $2.29 \times 10^{-3}$ & $1.46 \times 10^{-4}$ & -1.20 \\
2.54 & -4.127 & $1.013 \times 10^{-3}$ & $1.01 \times 10^{-2}$ & -0.3 & $9.49 \times 10^{-3}$ & $6.00 \times 10^{-4}$ & -1.46 \\
2.56 & -4.119 & $1.04 \times 10^{-3}$ & $9.61 \times 10^{-4}$ & -8 & $9.29 \times 10^{-4}$ & $3.25 \times 10^{-5}$ & -0.26 \\
2.65 & -3.006 & $2.44 \times 10^{-3}$ & $2.45 \times 10^{-3}$ & 0.4 & $1.59 \times 10^{-3}$ & $8.66 \times 10^{-3}$ & +0.23 \\
2.73 & -2.759 & $4.76 \times 10^{-3}$ & $4.97 \times 10^{-3}$ & 4.2 & $1.85 \times 10^{-3}$ & $3.13 \times 10^{-3}$ & -0.75 \\
2.8 & -3.582 & $2.43 \times 10^{-3}$ & $2.50 \times 10^{-3}$ & 2.8 & $2.13 \times 10^{-3}$ & $3.75 \times 10^{-4}$ & -2.53 \\
2.88 & -2.996 & $2.48 \times 10^{-3}$ & $2.42 \times 10^{-3}$ & -2.4 & $1.55 \times 10^{-3}$ & $8.68 \times 10^{-4}$ & -0.60 \\
2.89 & -3.492 & $4.94 \times 10^{-3}$ & $5.03 \times 10^{-3}$ & 1.7 & $4.01 \times 10^{-3}$ & $1.01 \times 10^{-3}$ \\
2.96 & -2.709 & $9.77 \times 10^{-3}$ & $1.02 \times 10^{-2}$ & 4.2 & $3.35 \times 10^{-3}$ & $6.86 \times 10^{-3}$ \\
3.24 & -3.952 & $2.61 \times 10^{-3}$ & $2.61 \times 10^{-3}$ & 0 & $2.28 \times 10^{-3}$ & $3.30 \times 10^{-4}$ \\
3.43 & -2.562 & $4.88 \times 10^{-3}$ & $5.02 \times 10^{-3}$ & 2.8 & $9.10 \times 10^{-4}$ & $4.11 \times 10^{-3}$
\end{tabular}

[A], molar concentrations of species A

$\Delta$, percentual difference between theoretical and calculated $\mathrm{U}(\mathrm{VI})$ total concentration

$R$, concentration ratio of $\mathrm{UO}_{2} \mathrm{CH}_{3} \mathrm{COO}^{+}$and $\mathrm{UO}_{2}{ }^{2+}$

spectrum for the U(VI) monoacetato species is applied to the deconvolution of experimentally obtained U(VI) spectra in acetate medium.

Table 2 also presents mean value results for the species concentrations from the deconvolution, the calculated free acetate concentrations, the total U(VI) concentrations, the respective $\mathrm{U}(\mathrm{VI})$ concentrations as obtained by summing the species concentrations, and a comparison of both U(VI) concentrations in per cent differences.

The quotient of species concentrations is obtained from the quantitative spectral deconvolutions, while the free acetate concentrations may be estimated on basis of the known total acetate concentration, the $\mathrm{pH}$, and the $\mathrm{p} K_{\mathrm{A}}$ of acetic acid. These quantities are given in Table 2. A graphical summary is given in Fig. 8 where parameters from Table 2 are interpreted by a trend with fixed slope 1 according to Eq. (1). The formation quotient $\lg \beta_{11}$ for $\mathrm{UO}_{2} \mathrm{CH}_{3} \mathrm{COO}^{+}$is defined as

$\lg \beta_{11}=\lg \frac{\left[\mathrm{UO}_{2} \mathrm{CH}_{3} \mathrm{COO}^{+}\right]}{\left[\mathrm{UO}_{2}^{2+}\right]}-\lg \left[\mathrm{CH}_{3} \mathrm{COO}\right]^{-}$

where [A] denotes molar concentrations of species A.

The intercept $\lg \beta_{11}$ is obtained as $2.8_{5} \pm 0.0_{5}$, where the uncertainty is given on the $95 \%$ level. The evaluation of a formation quotient has not been a main focus of this study because $\lg \beta_{11}$ has been previously determined by a variety of methods rather consistently. Respective presentations are available in literature (e.g. recently [12]). We note that the evaluation of this parameter on basis of the derived single component spectrum Fig. 4 falls within this range of literature data.
In the ionic strength range used here $(0.01<I<0.2)$, values in the range $2.4<\lg \beta_{11}<3.0$ have been reported. Notwithstanding a complete uncertainty analysis of the thermodynamic data, the reliability of $\lg \beta_{11}$ from this study is tentatively estimated as $\lg \beta_{11}=2.8 \pm 0.3$. While the dashed lines in Fig. 8 give the uncertainty of the slope, the dotted lines give the estimated uncertainty $(0.95 \%$ ) of predicting a further measurement value on basis of the existing ones. All experimental data points are found within that limit.

\section{Conclusions}

The $51 \mathrm{UV}-\mathrm{V}$ is spectra of $\mathrm{U}(\mathrm{VI})$ acetate in the concentration range from $9 \times 10^{-4} \mathrm{~mol} \mathrm{dm}{ }^{-3}$ to $1 \times 10^{-2} \mathrm{~mol} \mathrm{dm}^{-3}$ and the $\mathrm{pH}$ range from 1.9 to $\mathrm{pH} 5$ were registered. From these, a subset of 14 spectra holding only a single complexed species was obtained using submatrix analysis or computerassisted target factor analysis (CAT) [33, 34]. This procedure is routinely applied to resolve UV-Vis absorption data of complex systems, e.g. [37-39].

The single component spectrum is assigned to the $\mathrm{UO}_{2} \mathrm{CH}_{3} \mathrm{COO}^{+}$species. It is the only species to consider under given experimental conditions. In the given range of $\mathrm{pH}$, hydrolysis is the only possible interfering reaction. Great care has been taken to avoid hydrolysis species with amounts above $1 \%$.

The derived spectrum of the $\mathrm{UO}_{2} \mathrm{CH}_{3} \mathrm{COO}^{+}$species has a molar absorption of $17.8 \pm 1.0 \mathrm{dm}^{3} \mathrm{~mol}^{-1} \mathrm{~cm}^{-1}$ at the absorption maximum of the characteristic absorption band of U(VI) at $418 \mathrm{~nm}$. This spectrum is able to interpret the 


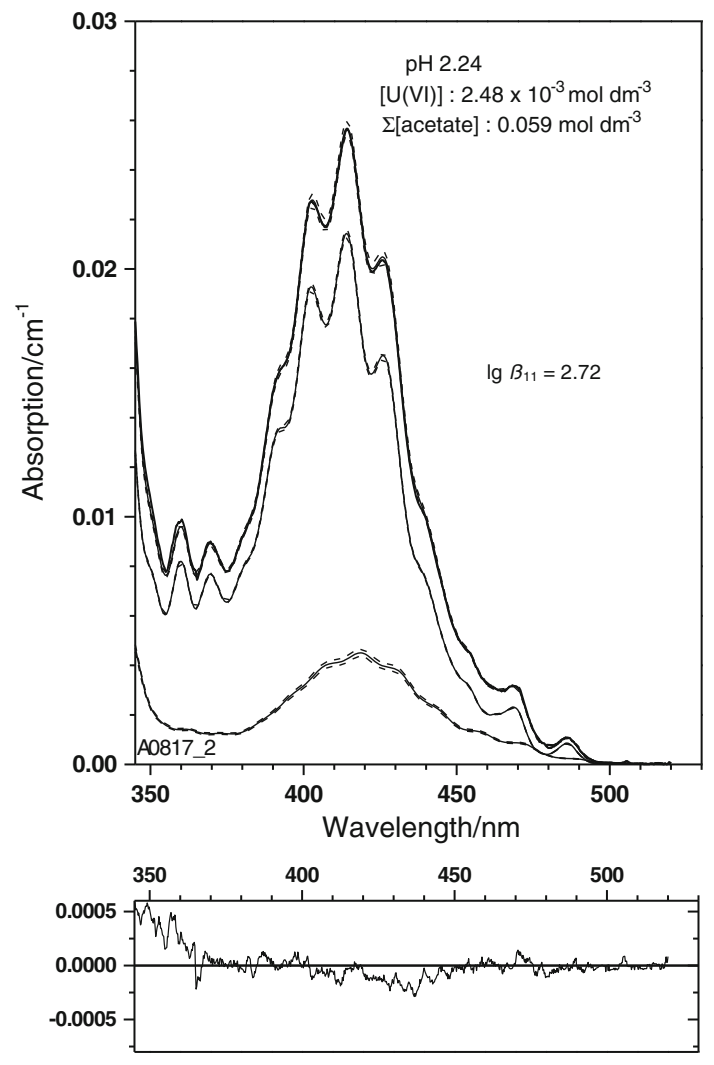

Fig. 5 Experimental U(VI) spectrum obtained at $\mathrm{pH} 2.24$ and total acetate concentration $\left(\mathrm{CH}_{3} \mathrm{COO}(\mathrm{H} / \mathrm{Na})\right)$ of $0.059 \mathrm{~mol} \mathrm{dm}^{-3}$. Under those conditions, the monoacetato species is a minor component only

14 spectra from which it was derived with only minor residuals. The total $\mathrm{U}(\mathrm{VI})$ concentrations in each of the 14 solutions is reproduced within a few percent.

From the relative species concentrations of $\mathrm{UO}_{2} \mathrm{CH}_{3-}$ $\mathrm{COO}^{+}$and $\mathrm{UO}_{2}{ }^{2+}$, the formation quotient could be derived as $2.85 \pm 0.05$, whereby the figure given after the ' \pm ' symbol is a $0.95 \%$ range but only accounting for the misfit of the regression line. It is not a complete measurement uncertainty budget.

The deconvolution of the spectra into the species' individual amounts has been done by a least square residuals criterion. The residuals contribute about $2-3 \%$ of the maximum absorption. With the exception of the spectrum at pH 2.96 given in Fig. 7, the residuals are unspecific. This single spectrum's residuals show a certain fine structure potentially indicative of a small contribution of another species-even if at the edge of detectability. Clearly, the availability of the $\mathrm{UO}_{2} \mathrm{CH}_{3} \mathrm{COO}^{+}$single component spectrum opens the chance to interpret more complex spectra, e.g. those recorded in a range of physical conditions where interference by hydrolysis is possible. Characterisation of hydrolysis components is relevant to avoid misinterpretation as higher acetate complexation. This will be the focus of our future activities.

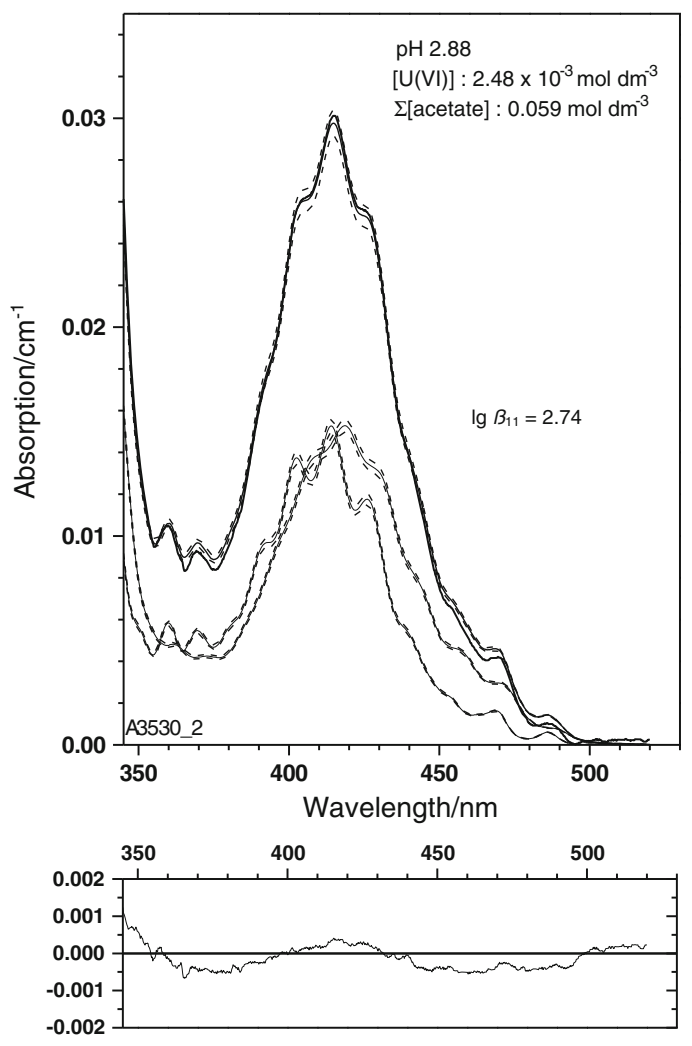

Fig. 6 Experimental U(VI) spectrum obtained at $\mathrm{pH} 2.88$ and a total acetate concentration $\left(\mathrm{CH}_{3} \mathrm{COO}(\mathrm{H} / \mathrm{Na})\right)$ of $0.059 \mathrm{~mol} \mathrm{dm}^{-3}$. Conditions are shown where both species have an almost equal spectral contribution

\section{Experimental}

Total U(VI) concentrations were in the range $9 \times 10^{-4} \mathrm{~mol} \mathrm{dm}^{-3}$ to $1 \times 10^{-2} \mathrm{~mol} \mathrm{dm}^{-3}$. The range of pH was varied between 1.9 and 5.0. Total acetate concentration was varying between 0.003 and $0.14 \mathrm{~mol} \mathrm{dm}^{-3}$. From these information, free acetate concentrations varying between $7.7 \times 10^{-5}$ and $5.8 \times 10^{-2} \mathrm{~mol} \mathrm{dm}^{-3}$ are obtained from numerical speciation.

$\mathrm{U}(\mathrm{VI})$ perchlorate solutions were prepared from $\mathrm{UO}_{2}\left(\mathrm{CH}_{3} \mathrm{COO}\right)_{2} \cdot 2 \mathrm{H}_{2} \mathrm{O}$ solid (CHEMAPOL/LACHEMA Co., Warsaw, Poland) by dissolution in water and re-precipitation with $\mathrm{H}_{2} \mathrm{O}_{2}(20 \%)$. The yellow precipitate was filtered, washed, and heated in a furnace at $200{ }^{\circ} \mathrm{C}(4 \mathrm{~h})$ and $400{ }^{\circ} \mathrm{C}(8 \mathrm{~h})$. The resulting $\mathrm{UO}_{3}$ solid was redissolved in a stoichiometric amount of perchloric acid (70\%, Fluka Co., Switzerland). A more detailed description of the procedure is given in [40]. The acetate medium was prepared from a standard solution of $0.3 \mathrm{M} \mathrm{NH}_{4} \mathrm{CH}_{3} \mathrm{COO}$ (POCH S.A. Co., Gliwice, Poland).

Numerical modelling of the sample solutions indicates that ionic strength of the samples varies between $I=0.01$ and $I=0.3$, hence is found outside the range of diluted 


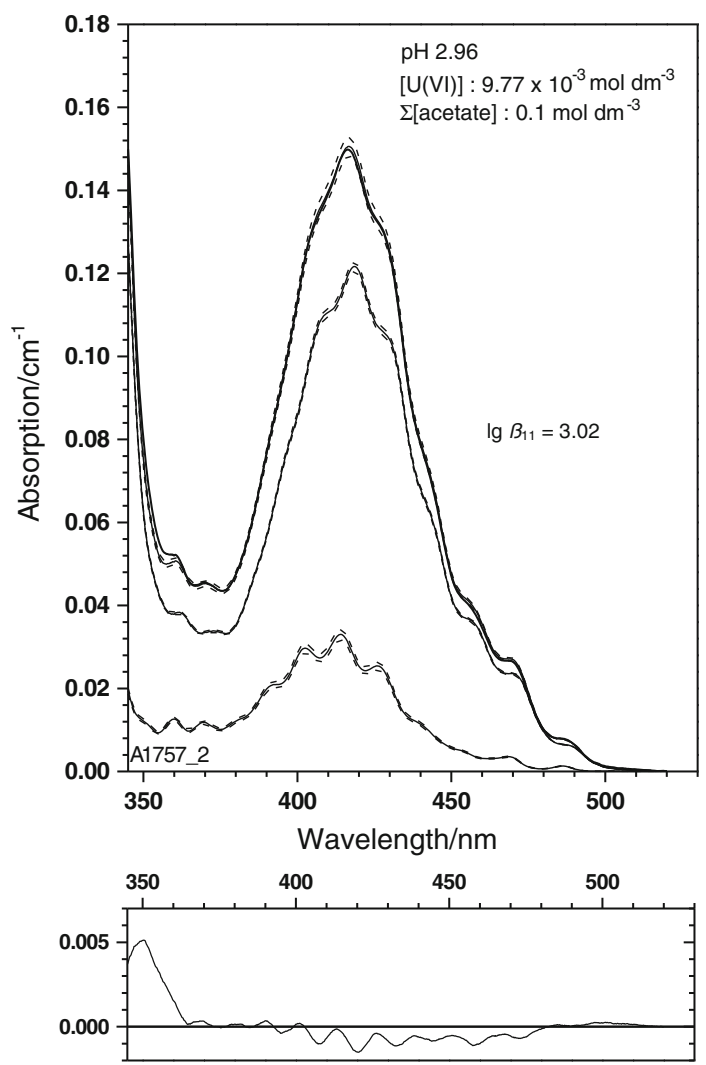

Fig. 7 Experimental U(VI) spectrum obtained at $\mathrm{pH} 2.96$ and a total acetate concentration $\left(\mathrm{CH}_{3} \mathrm{COO}(\mathrm{H} / \mathrm{Na})\right)$ of $0.1 \mathrm{~mol} \mathrm{dm}^{-3}$. Here, the $\mathrm{U}(\mathrm{VI})$ monoacetato species is the predominant spectral component

solutions where the thermodynamic parameters become highly sensitive to small changes of composition. All experimentation, if not stated otherwise, was made at room temperature.

\section{Apparatus and data collection}

A double-beam UV-Vis spectrometer (UV-2401 PC, Shimadzu Co., Japan) was used for collecting absorptions in the UV-Vis range. Spectra were recorded quadruply and averaged for noise reduction. Samples were placed in quartz cells with $20 \mathrm{~mm}$ path length and recorded digitally in the wavelength range $345-570 \mathrm{~nm}$ in $0.1 \mathrm{~nm}$ steps with a slit width of $1 \mathrm{~nm}$.

Determination of $\mathrm{pH}$ was made by a glass combination electrode (ELMETRON pH-meter Cp-315 Co., Zabrze, Poland) following the 5-point calibration scheme described by IUPAC [41, 42]. The calibration $\mathrm{pH}$ standard solution was traceable material (Merck Co., Darmstadt, Germany).

\section{Data analysis}

Speciation was made with the geochemical code PREEEQC [43] and the probabilistic speciation code

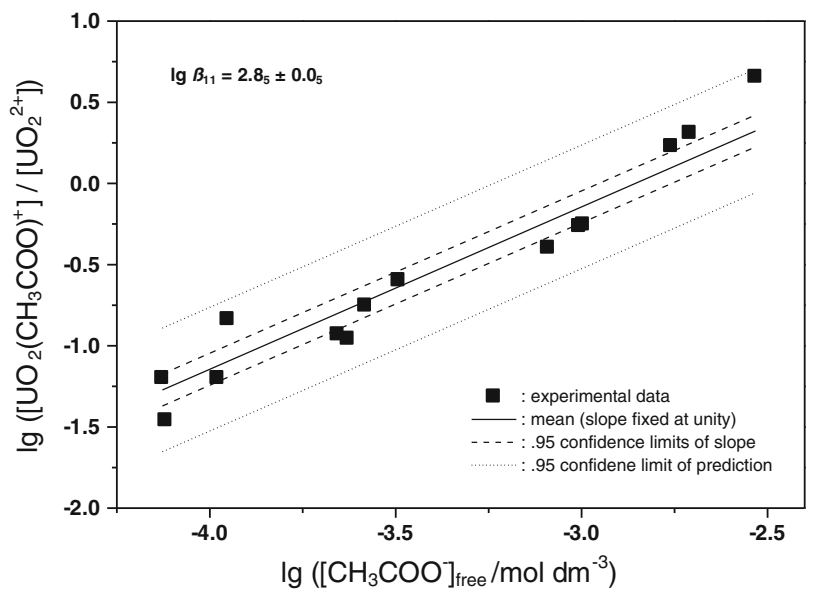

Fig. 8 Interpretation of the numerically determined species ratios $\mathrm{R}$ by the calculated free acetate $\left(\mathrm{CH}_{3} \mathrm{COO}^{-}\right)$concentration. The doublelogarithmic plot yields formation constant $\lg \beta_{11}$ as the $y$-intercept with the theoretical slope of 1 . Dashed lines give $0.95 \%$ uncertainty of the slope. The dotted lines give $0.95 \%$ uncertainties of predicting a further point

LJUNGSKILE [44]. Geochemical modelling is based on the parameters given in Table 1. Thermodynamic data, if not given otherwise, are taken from the JESS Thermodynamic Database [45, 46]. Spectral deconvolutions are made with custom-made codes based on the sequential Simplex [47] using least-squares criteria. Variance-covariance matrices and uncertainties of the spectral curves are estimated from quadratic forms in the minimum of the numerical optimum [48]. If not stated otherwise, uncertainties are given as $68 \%$ confidence intervals. For data derived from small sample sizes, the necessary corrections have been made to transform standard deviations into confidence regions. The uncertainties in spectral decompositions (cf. Figs. 5, 6, 7) are given on the $0.95 \%$ range. None of the uncertainties represents a complete measurement uncertainty budget since only statistical contributions to uncertainty (e.g. misfit) are considered.

Open Access This article is distributed under the terms of the Creative Commons Attribution License which permits any use, distribution, and reproduction in any medium, provided the original author(s) and the source are credited.

\section{References}

1. Majer V, Sedlbauer J, Hnedkovsky L, Wood RH (2000) Phys Chem Chem Phys 2:2907

2. Spitzer P, Fisicaro P, Meinrath G, Stoica D (2011) Accred Qual Assur 16:191

3. Denning RG (1983) Properties of the $\mathrm{UO}_{2}^{\mathrm{n}+}(\mathrm{n}=1,2)$ Ions. In: Gmelin Handbuch der anorganischen Chemie: Uran (Supplement) A6:31

4. Meinrath G, Kato Y, Kimura T, Yoshida Z (1996) Z Radiochimica Acta 75:159 
5. Meinrath GJ (1997) Radioanal Nucl Chem 224:119

6. Grigoriev MS, Antipin MYu, Krot NN (2005) Acta Cryst E61:2078

7. Vologzhanina AV, Serezhkina LB, Neklyudova NA, Serezhkin VN (2009) Inorg Chim Acta 362:4921

8. Serezhkina LB, Vologshanina AV, Klepov VV, Sereshkin VN (2011) Crystallogr Rep 56:132

9. Chien W, Anbalagan V, Zandler M, Van Stipdonk M, Hanna D, Gresham G, Groenewold GJ (2004) Am Soc Mass Spectrom 15:777

10. Bailey EH, Mosselmans JF, Schofield PF (2004) Geochim Cosmochim Acta 68:1711

11. Kirishima A, Onishi Y, Sato N, Tochiyama O (2007) J Chem Thermodyn 39:1432

12. Sladkov V (2013) J Chromatogr A 1289:133

13. De Jong WA, Apra E, Windus TL, Nichols JA, Harrison RJ, Gutowski KE, Dixon DA (2005) J Phys Chem A109:11568

14. Ray RS, Krüger S, Rösch N (2010) Inorg Chim Acta 363:263

15. Groenewold GS, de Jong WA, Oomens J, Van Stipdonk M (2010) J Am Mass Spectrom 21:719

16. Lucks C, Rossberg A, Tsushima S, Foerstendorf H, Scheinost AC, Bernhard G (2012) Inorg Chem 51:12288

17. Vazquez J, Bo C, Poblet JM, de Pablo J, Bruno J (2003) Inorg Chem 42:6136

18. Quilès F, Burneau A (1998) Vib Spectrosc 18:61

19. Nguyen-Trung C, Begun GM, Palmer DA (1992) Inorg Chem 31:5280

20. Jiang J, Rao LF, di Bernardo P, Zanonato PL, Bismondo A (2002) J Chem Soc Dalton Trans, 1832

21. Bailey EH, Mosselmans JFW, Schofield PF (2004) Geochim Cosmochim Acta 68:1711

22. Paramonova V, Kolychev V (1966) Radiokhimiya 8:304

23. Ahrland S (1951) Acta Chem Scand 5:199

24. Miyake C, Nurnberg HW (1967) J Inorg Nucl Chem 29:2411

25. Nikolsky B, Kolychev V, Grekovich A, Paramonova V (1960) Radiokhimiya 2:330
26. Görrler-Walrand C, de Jagere S (1972) Spectrochim Acta 28A:257

27. Meinrath G (1997) J Radioanal Nucl Chem 224:119

28. Meinrath G, Schweinberger M (1996) Radiochim Acta 75:205

29. Meinrath G (1997) Radiochim Acta 77:221

30. Meinrath G (1998) J Radioanal Nucl Chem 232:179

31. Meinrath G, Klenze R, Kim JI (1996) Radiochim Acta 74:81

32. Meinrath G, Kato Y, Kimura T, Yoshida Z (1996) Radiochim Acta $75: 159$

33. Cartwright H (1987) J Chemometrics 1:111

34. Meinrath G, Lis S (2001) Fresenius J Anal Chem 369:124

35. Cattell RB (1966) Multivariate Behav Res 1:245

36. Meinrath G (2000) Anal Chim Acta 415:105

37. Meinrath G, Hnatejko Z, Lis S (2004) Talanta 63:287

38. Kaczmarek M, Meinrath G, Lis S, Kufelnicki A (2008) J Solution Chem 37:933

39. Meinrath G, Lis S, Piskula Z, Glatty Z (2006) J Chem Thermodyn 38:1274

40. Park Y-Y, Sakai Y, Abe R, Ishii T, Harada M, Kojima T, Tomiyasu H (1990) J Chem Soc Faraday Trans 86:55

41. Buck RP, Rondinini S, Covington AK, Baucke FGK, Brett CMA, Camoes MF, Milton MJT, Mussini T, Naumann R, Pratt KW, Spitzer P, Wilson GS (2002) Pure Appl Chem 74:2169

42. Spitzer P (2001) Accred Qual Assur 6:45

43. Parkhurst DL, Appelo CAJ (2013) US Geological Survey Techniques and Methods, book 6, chap A43. US Geological Survey, Denver

44. Ödegaard-Jensen A, Ekberg C, Meinrath G (2004) Talanta 63:907

45. May PM, Rowland D, Murray K. Joint expert speciation system (JESS Thermodynamic Database). http://jess.murdoch.edu.au. Accessed May 2014

46. May PM, Murray K (2001) J Chem Eng Data 46:1035

47. Nelder JA, Mead R (1965) Comput J 7:308

48. Brumby S (1989) Anal Chem 61:1783 